Article

\title{
Serotiny in Primula palinuri: How to Face the Dry Season on Mediterranean Cliffs
}

\author{
Roberto Silvestro ${ }^{1,2}$, Luigi Gennaro Izzo ${ }^{1, * \mathbb{C}}$, Maurizio Buonanno ${ }^{3}$ and Giovanna Aronne ${ }^{1}$ (D) \\ 1 Department of Agricultural Sciences, University of Naples Federico II, Via Università 100, \\ 80055 Portici, Italy; roberto.silvestro1@uqac.ca (R.S.); aronne@unina.it (G.A.) \\ 2 Département des Sciences Fondamentales, Université du Québec à Chicoutimi, 555 boulevard \\ de l'Université, Chicoutimi, QC G7H2B1, Canada \\ 3 Institute for Mediterranean Agricultural and Forestry Systems (ISAFoM), National Research Council (CNR), \\ P.le Enrico Fermi 1-Loc. Porto del Granatello, 80055 Portici, Italy; maurizio.buonanno@cnr.it \\ * Correspondence: luigigennaro.izzo@unina.it
}

Received: 9 June 2020; Accepted: 22 July 2020; Published: 25 July 2020

\begin{abstract}
Primula palinuri Petagna is the only Mediterranean and maritime species in the genus Primula, is endemic to coastal cliffs of southern Italy, and is classified as endangered with a decreasing population trend in the IUCN Red List. For this species, the major bottleneck for long-term survival has been recognized to be recruitment failure. In this study, we investigated the seed release strategy of P. palinuri, by using field observations and laboratory experiments. We hypothesized that repetitive cycles of wet/dry conditions and external wax removal could be the environmental triggers of capsule dehiscence. Data showed that capsules treated with wet/dry cycles dehisced within 75 days, while none subjected to constant dry conditions dehisced. Once dehisced, capsules repetitively closed when made wet, and opened again upon drying. Seeds of P. palinuri can remain on plant up to 2 years, over which time capsules reclose when rained upon and reopen upon drying, highlighting the first reported occurrence of serotiny in a Primula species. Serotiny allows P. palinuri to face the dry season, by avoiding capsule dehiscence during the summer dry period and delaying seed release until the beginning of fall, when water availability in the soil is generally no longer a limiting factor.
\end{abstract}

Keywords: mediterranean habitat; plant conservation; species ecology; mediterranean endemism; aerial seed bank

\section{Introduction}

Glacial advancement across Europe fragmented once-continuous populations that later differentiated in isolation [1]. Many relict species can be found on cliffs in Mediterranean region that once served as glacial refugia [2]. Vertical cliffs are habitats generally restricted to high and very steep rock walls, characterized worldwide by a set of peculiar environmental factors due to verticality [3]. Among other physical factors, gravity affects cliff environments, because it removes all unstable material including rocks, soil, water, litter and seeds. Moreover, water movement through the rocks can either remove or concentrate soil particles and organic debris locally on ledges. Similarly, water run-off can disperse, but also completely eliminate, seeds from the system [3]. The peculiar interaction of the environmental factors typical of cliffs has exerted a strong selective pressure on the traits of plants living in this habitat, and the results of this evolutionary process can be quite successful in promoting the survival of many cliff species when compared to their congeners. This might have led to notably higher rates of survival of phylogenetic relicts and rare species occurring on cliffs than in the flora of the surrounding areas [3-7].

Primula is a widely distributed genus of Primulaceae, consisting of ca. 430 species [8]. Historically, primulas have been a model for the study of the evolution of plant breeding systems [9], and represent 
an important group of garden plants [8]. Although primulas are often found in montane habitats [8], specific microhabitats can vary from open meadows for $P$. farinosa $[8,10]$ or closed-canopy forests for P. veris [11], to cliff habitats for P. scotica [12], P. cusickiana var. maguirei [13], P. apenninica [14] and P. boveana [15]. Primula palinuri is the only Mediterranean and maritime species of the sect. Auricula [16], and more in general in this genus [17]. Currently, this species is included in the IUCN (International Union for Conservation of Nature) red list, classified as "Endangered", with a decreasing population trend. The natural habitat of P. palinuri is limited to the vertical cliffs occurring in Cilento along the Tyrrhenian coast of Southern Italy, with a spotty distribution along a narrow area of less than $100 \mathrm{~km}[18,19]$. Access to these sites is difficult, and new approaches to monitor P. palinuri and other species on coastal cliffs have been proposed [20].

The major bottleneck in the survival of this species is known to involve recruitment failure [18]. Nevertheless, studies on seed release, dispersal and germination are lacking. In this species, individual plants flower regularly, mature capsules produce tens of viable seeds and are supported by terminal umbels [18,21,22]. Moreover, it is one of relatively few Mediterranean species that flower in winter $[17,22]$. This adaptive trait allows plants to harden and mature capsules before summer. The adaptation of phenological timing of growth and reproduction to fulfill the reproductive cycle between the end of winter and the beginning of summer is a strategy to avoid the limiting conditions of low winter temperatures and summer drought typical of the Mediterranean region [23-25]. In P. palinuri, water availability surely plays a leading role in seedling survival. Indeed, seeds are retained in the capsules throughout the summer, and seed release is synchronized with the first rainfall events at the beginning of autumn [17].

The term "seed bank" is generally referred to as the reserve of viable and non-germinated seeds stocked in a habitat [26]. The higher the probability of reproductive failure in any single year, the higher becomes the return on a species' investment in the development of a seed bank [27]. Although the term seed bank is commonly with soil, seeds can also be stored on mother plants (aerial seed bank). Worldwide, more than 1200 species rely on this strategy, retaining seeds in their canopy for 1-30+ years [28]. Overall, aerial seed storage is an ecological advantage by building up a seed reserve until conditions are better-suited to seedling establishment $[29,30]$.

Species with aerial seed banks are commonly referred to as "serotinous" [31], a further adaptive trait, in which seed release occurs in response to an environmental trigger. Serotiny has usually been associated with fire-induced seed release in various fire-controlled ecosystems, from Mediterranean scrublands [32,33] or North American chapparal [34] to boreal stands [35]. Although most literature about serotiny focuses on fire-prone ecosystems, serotinous species have been documented in many environments in which other drivers can act as the signal for seed release [27]. In Mediterranean and desert plants, where water availability can represent the major bottleneck for seed germination and seedling establishment, a reverse mechanism operates compared with fire-prone environments. An initial desiccation seals the seeds into lignified structures that will open to release the seeds with the occurrence of rain $[36,37]$. In this case, the rain causes an hygrochastic opening, defined as the dehiscence of a fruit in response to the presence of moisture [38]. Such a strategy has been widely studied in plants from Aizoaceae: they respond to rainfall by opening capsules that will close again once desiccated [38], in a repeating cycle that is perpetuated until the best conditions for germination occur.

For desert species, serotiny is considered an effective adaptive trait to cope with extreme environments and reduce the risk of offspring mortality [39]. For this reason, it is presumable that a similar strategy has evolved in other environments where water availability is a limiting factor. Given that P. palinuri seeds are retained in mature capsules throughout the summer and seed release occurs with the first rainfall events at the beginning of autumn [17], the aim of this work was to investigate the strategy of seed release adopted by this species to deal with the harsh conditions of vertical cliffs. Accordingly, the following hypothesis was tested: P. palinuri is a serotinous species in which seeds are stored in the aerial seed bank and released in response to specific environmental triggers. 


\section{Materials and Methods}

\subsection{Field Sites and Plant Materials}

Research on seed release in P. palinuri was performed, combining both field and laboratory observations and experiments. Field activities were performed within the native range of $P$. palinuri at Cilento National Park, and more specifically at Palinuro Marinella, (40 01'56" N 15 $17^{\prime} 54^{\prime \prime}$ E), and at

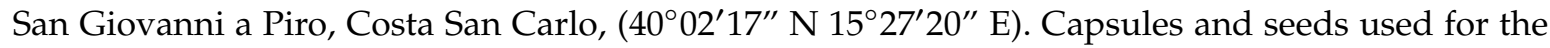
laboratory experiments were collected from plants germinated from wild seeds grown in the open-air rockery of the Botanical Garden of Portici $\left(40^{\circ} 48^{\prime} 4^{\prime \prime} \mathrm{N} 14^{\circ} 20^{\prime} 3^{\prime \prime} \mathrm{E}\right)$.

\subsection{Capsule Dehiscence}

The effect of cycles of dry and wet conditions on capsule dehiscence was measured by conducting a laboratory test. Capsules used for the experiment were sampled by collecting mature, lignified capsules at the end of summer 2018. To ensure a uniform distribution of plant material and avoid genetic bias, we sampled 8 umbels of mature capsules from 10 plants, for a total of 80 capsules. Although temperatures reflecting real conditions in the field would have been preferable, they were difficult to resemble. Therefore, we decided to exclude temperature as a variable and performed the experiment in a growth chamber at a constant temperature of $20^{\circ} \mathrm{C}$.

Moreover, 20 capsules were kept constantly in a dry condition; another 20 were exposed to cycles of wet and dry conditions ( $12 \mathrm{~h}$ in dry condition and $12 \mathrm{~h}$ in wet condition). We avoided testing the effect of constant wet conditions, considering that these conditions are unlikely to occur in the field, even during the winter. Dry condition was obtained by lining containers with abundant anhydrous silica gel. Wet condition was obtained by sprinkling tap water on the capsules until the bottom of the containers was filled with approximately $5 \mathrm{~mm}$ of water. The number of dehisced capsules was daily recorded for 75 days.

The effect of wax removal on dehiscence was tested, considering that in the field dehisced capsules usually had lost their wax coating, and hypothesizing that the hydrophobic wax act as an insulating layer by preventing an immediate and direct contact of water with capsules. Wax removal was performed by cutting the apical part of the calyces that partially cover the capsules and mechanically, removing the wax layer from capsules with a paper tissue. Although a chemical solvent would have guaranteed a more effective wax removal, we decided to avoid potential alterations to the capsules surface. Furthermore, 20 capsules with wax unremoved and 20 capsules in which wax was removed were exposed to cycles of wet and dry conditions ( $12 \mathrm{~h}$ in dry and $12 \mathrm{~h}$ in wet conditions). The number of open capsules was daily recorded, until all the capsules of both the treatments (i.e., wax removed and wax unremoved) dehisced, for a total of 75 days.

\subsection{Field Experiments: Seed Storage}

\subsubsection{Storage in Aerial Seed Bank}

Seed storage on plants was verified in two natural populations of P. palinuri in the National Park of Cilento. Studies on reproductive ecology of $P$. palinuri showed that, each year, plants can develop a single umbel on a long scape [22]. Nevertheless, in field surveys, we observed that inflorescences can persist on plants for more than one year. Accordingly, seed storage on plants was tested by counting the seeds stored in umbels of different ages. In October 2018, we selected plants that retained more than one umbel, and counted the number of seeds per capsule from 10 such plants per site. Inflorescence age was defined based on the position on the stem. Therefore, we could compare the number of seeds retained in inflorescences of different ages. 


\subsubsection{Storage in Soil Seed Bank}

Seed persistence in soil bank was tested in two natural populations of P. palinuri in the National Park of Cilento. Considering the steep slope, four locations at each site were identified, based on the proximity of reproducing plants and physical accessibility. In each location, we set up six lots of 50 seeds in cages covered by a flexible net to facilitate the count. Both the cage and the net were designed to ensure seed access for soil-dwelling granivores, and avoid seed run-off by rain or wind. Seed counts in the field were planned twice a month.

\subsection{Statistical Analysis}

\subsubsection{Capsule Dehiscence and the Effect of Wax Removal}

The effect of cycles of alternating wet and dry conditions and, subsequently, of wax removal on the timing of capsule dehiscence, were tested by performing a lifetime analysis. The heterogeneity among treatments was tested by the log-rank test [40]. While the lifetime analysis was sufficient for explaining the effect of cycles of wet and dry conditions on capsule dehiscence, we also conducted an accelerated failure time (AFT) model to measure the effects of wax removal. AFT models assume only that a baseline survival function is modified (i.e., accelerated) by a regression of event times on covariates [40]. Therefore, AFT models evaluate the extent to which the baseline survival function is shifted to the right or left, by covariates such as population, treatment, or emergence date [40]. In our model, the survival curve of capsules with wax unremoved was chosen as the baseline survival function. A log-normal distribution was used for the AFT model, because it gave the best fitting model. Finally, significance of each regression parameter was evaluated with log-likelihood tests [41]. Statistics were calculated by using R version 3.5.2 [42].

\subsubsection{Seed Storage on Plants}

Seed storage on plants was tested by performing a one-way analysis of variance (ANOVA). To establish a normal distribution and homogeneity of data, a log-transformation was performed. These analyses were followed by Tukey's HSD grouping tests, to identify heterogeneous groups. Statistics were calculated by using R version 3.5.2 [42].

\section{Results}

\subsection{Capsule Dehiscence}

Repetitive wet and dry cycles served as the main environmental factor triggering capsule dehiscence. The experiment lasted 75 days, corresponding to the period in which all treated capsules dehisced (Figure 1). During the same period, none of the capsules subjected to constant dry condition dehisced, corroborating our previous observation that undehisced capsules remain closed for several years when stored dry (Figure 1). The shortest time that led to a dehisced capsule was 8 days, while the longest was 75 days. The median predicted by survival curves for dehiscence was 34.5 days. The progressive reduction of undehisced capsules (survival curves) resulted in a highly significant difference between treatment $\left(x^{2}=23.4, d f=1, p<0.0001\right)$. By focusing only on the treatments involving cycles of wet-dry conditions, dehiscence timing was lower in capsules where wax was removed than in capsules with wax retained (Figure 1). The time to reach the dehiscence of all capsules from which wax was removed ranged between 8 and 30 days, with a predicted median of 12 days. The lifetime analysis showed significant heterogeneity among treatments (Figure 1, Table 1). The regression coefficients in Table 1 and their estimated covariance showed that wax removal can effectively speed up the dehiscence process. 


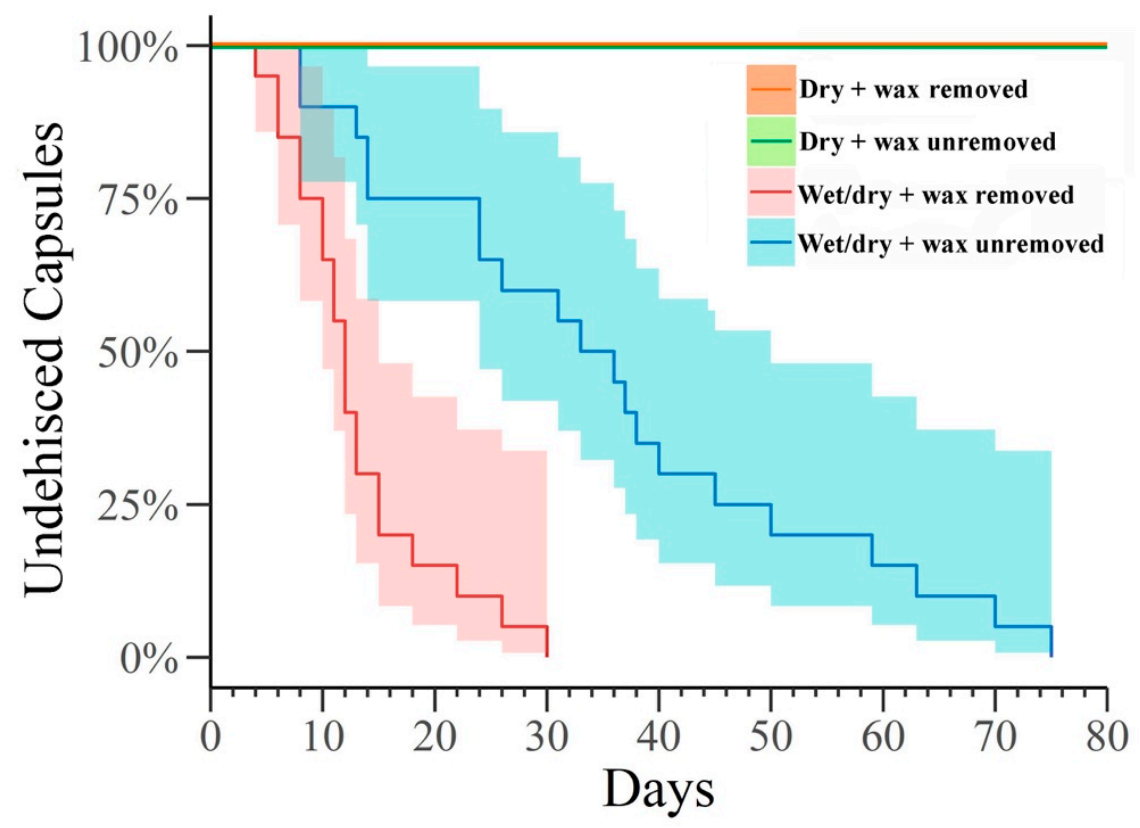

Figure 1. Progressive reduction of the number of undehisced capsules of Primula palinuri. Results of both the effect of cycles of wet and dry conditions and those of wax removal are presented here. Shaded areas represent the $95 \%$ confidence interval.

Table 1. Analysis of accelerated failure-time model for P. palinuri capsule dehiscence, based on log-normal distribution.

\begin{tabular}{ccccc}
\hline Variable & $d f$ & $\begin{array}{c}\text { Parameter } \\
\text { (SE) }\end{array}$ & $\chi^{2}$ & $p$-Value \\
\hline Intercept & 1 & $2.46(0.13)$ & 49.31 & $<0.001$ \\
Treatment & 1 & & 19.67 & $<0.001$ \\
(Wax removed) & 1 & $-0.92(0.18)$ & 19.67 & $<0.001$ \\
(Wax unremoved) & 0 & 0.00 & & \\
Scale parameter & 1 & $0.55(0.11)$ & & \\
Maximized log-likelihood $=-151.50$ & & \\
\hline
\end{tabular}

Working in the field, another unexpected mechanism has been observed and subsequently confirmed with laboratory tests. After capsule dehiscence triggered by cycles of wet-dry conditions, a further mechanism controls seed release. Dehisced capsules interact with water: promptly close when wet and slowly open again upon drying (Figure 2). This open-close mechanism has been observed up to the end of the experiment.

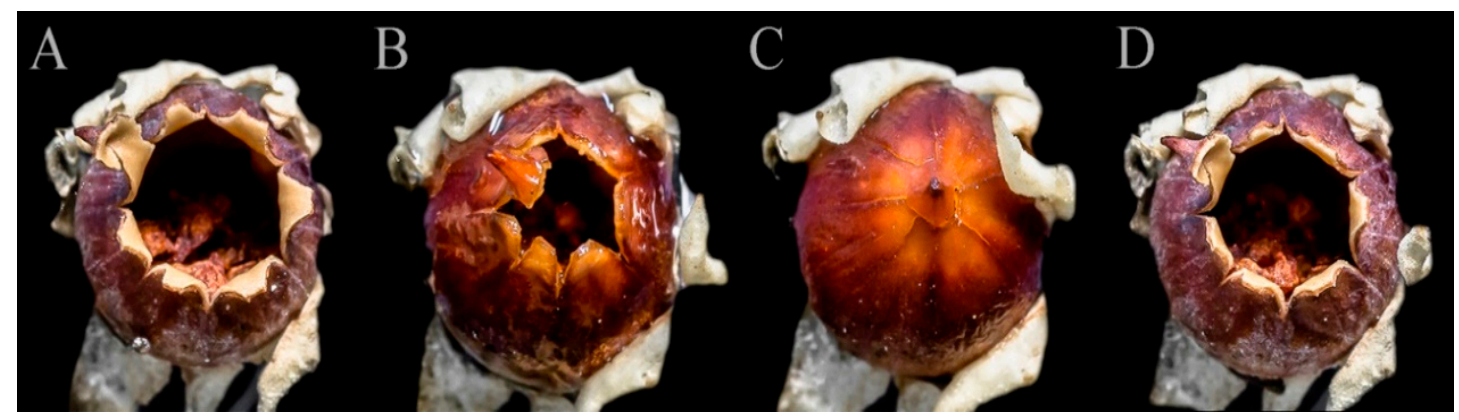

Figure 2. Hygroscopic movement of P. palinuri capsules: (A) dry capsule; (B) capsules wetted with sprinkling distilled water; (C) end of closing process, average duration $10 \mathrm{~min}$; (D) reopening due to drying out, average duration $120 \mathrm{~min}$. 


\subsection{Aerial and Soil Seed Bank}

Data on the reproductive phenology of P. palinuri showed that capsules look mature and dry in July; some of them show first cracks on the apex in August, and start to dehisce and disperse the seeds in October.

Field data revealed that $P$. palinuri can develop an aerial seed bank, lasting up to two years (Figure 3). Nevertheless, our results show that most of the seed release occurs during the year of capsule maturation and dehiscence. Indeed, the number of seeds stored in capsules greatly decreases in one-year-old inflorescences, with only a few seeds retained in the capsules of two-year-old umbels (Figure 3). No plant with more than three umbels was found in the field.

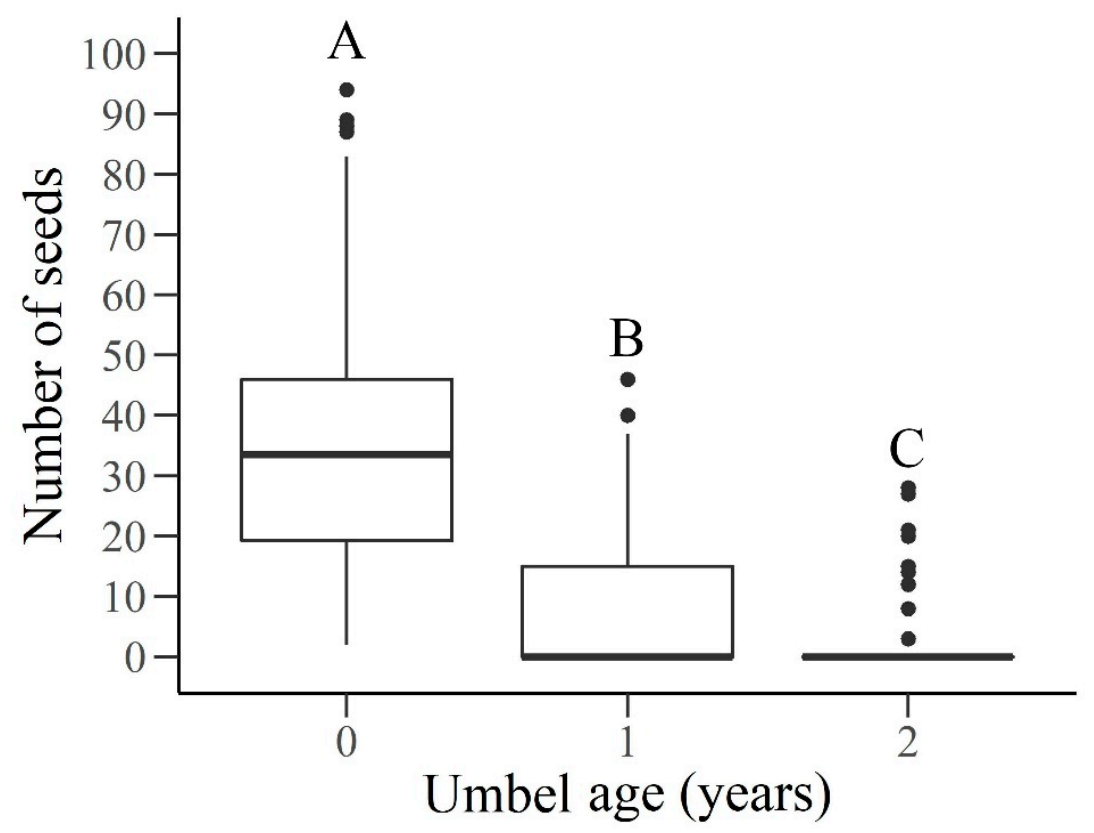

Figure 3. Number of seeds in Primula palinuri inflorescences of different ages.

Results of the soil seed bank test showed a total removal of P. palinuri seeds from the soil surface. After 15 days, none of the 2400 seeds used for the test were found in the cages placed in all microsites. Although no specific test was performed and further analyses are still needed, during field activities, it was observed that seeds were picked up by ants. Considering the elevated activity of granivorous ants (Messor spp.) in the experimental sites, some seeds of P. palinuri were spread along the ants' trail, and their removal was video recorded to document seed movement by ants (Video S1).

\section{Discussion}

\subsection{Serotiny in P. palinuri}

We investigated the seed release strategy adopted by P. palinuri on the vertical cliffs along the Tyrrhenian coast of southern Italy, highlighting, for the first time, the occurrence of serotiny in Primula species. As already pointed out, seedling establishment is a critical phase in the life cycle of P. palinuri [18], in which water availability surely plays a leading role [17]. Our results demonstrate that $P$. palinuri is a serotinous species in which seed release occurs only in response to cycles of moisture following dry periods. From an ecological point of view, this strategy is analogous to that of species in arid environments, such as in the large family Aizoaceae [27,38]. In that family, $98 \%$ of its species possess hygrochastic capsules that open when moistened and close again when dry [38]. Therefore, the occurrence of seed release is strictly related to water availability, regulated by the intensity of rainfall events. Capsules of Aizoaceae must be thoroughly wetted by a heavy rain before they open to 
release seeds [38]. Differently, in P. palinuri, a single rainfall event, even if particularly intense, is not enough to trigger seed release. Our results highlight that repetitive cycles of wet and dry conditions are necessary to trigger capsule dehiscence. In Mediterranean plant communities, this mechanism has been observed in Cistus ladanifer and C. libanotis [37].

Capsules of P. palinuri are covered by a thick layer of white hydrophobic wax, consistent with the "farinose wax" typically reported in Primulaceae [43]. We can infer that the hydrophobic wax acts as an insulation layer, by preventing direct contact of water with the capsule. Similarly, the presence of superhydrophobic surfaces in Eokochia saxicola, another endangered species surviving on the same cliffs as P. palinuri, is reported as an adaptation to cope with the environment $[44,45]$. Falling raindrops induce wax erosion by damaging the delicate wax crystalline structures of leaves [46]. In our study, the dehiscence mechanism most likely starts only after the removal of the farinose wax. Furthermore, mechanical removal of the wax accelerated capsule dehiscence in P. palinuri, likely making a preferential access to the capsule surface for water. In this species, the timing of wax removal seems to reflect the timing of capsule dehiscence. Therefore, any process that induces wax degradation could promote faster capsule dehiscence.

\subsection{From What We Know to What Is Still Missing}

Once capsules open, all seeds are not released at the same time. Indeed, capsules repeatedly open when dry and close again when moistened. Likely, this mechanism allows plants to gradually distribute their seeds over time from a long-lasting aerial seed bank [30]. Clearly, an aerial seed bank would be useless if the seeds do not remain viable [47]. In addition to the yearly production of capsules, plants of P. palinuri retain old capsules with seeds up to 2 years old. In this regard, we are collecting data to examine the relationship between the duration of seed viability and that of seed storage on plants.

Our observations are in contrast with a common assumption about serotiny, that all seeds are released simultaneously, and must germinate during the first wet season [28]. However, this statement mostly mirrors serotinous species evolved in fire-prone ecosystems. In contrast, where water availability is a limiting factor and the major bottleneck is the transition of seeds to seedlings, the ability to distribute seed release over time can be interpreted as an opportunistic strategy to cope with the uncertainty of environmental conditions [30,33]. However, despite this mechanism to store seeds on the plant and, subsequently, distribute their release over time, which likely evolved to favor the transition of seeds to seedlings, recruitment failure is still one of the main issues in P. palinuri conservation. Typically, less than $10 \%$ of the seeds released become seedlings, among many serotinous species [48]. Nevertheless, the reasons behind this phenomenon remain unclear and worthy of further study.

Species belonging to meadows or underbrush communities benefit from long-distance seed dispersal, by establishing meta-populations in transient favorable habitats [49,50]. This strategy often exploits water surface run-off or animal-mediated dispersal (e.g., rodents, birds or ants) [11]. In contrast, species inhabiting cliffs generally adopt a strategy in which seed shadows remain close to the mother plant $[14,15]$. In P. palinuri, while serotiny allows seed release to meet better-suited environmental conditions for germination and seedling establishment, the subsequent mechanism in which capsules promptly closeup when wet and open again upon drying can also be interpreted as a strategy to reduce seed losses due to surface run-off. The strategy for seed release adopted by P. palinuri seems to be a clear adaptive trait to avoid summer drought and await better conditions for seedling establishment. Nevertheless, maritime vertical cliffs along the Tyrrhenian coast of southern Italy interface directly with the sea, thus resulting in an extreme limit for terrestrial flora expansion [6]. Therefore, if water availability is an essential condition for seedling emergence [17], surface run-off during rainfall events represents a high risk for seed losses. Once seeds of $P$. palinuri are released, they develop hypocotyl hairs, which enhance water absorption and ensure mechanical support [21]. This need to prevent run-off loss likely explains differences in seed release between P. palinuri and species distributed in other arid environments. In desert plants, rain is the main seed-release trigger, but it is also the main dispersal agent $[36,38,47]$. Once the strategy of seed release is understood, it is 
then critical to investigate the dispersal strategy in P. palinuri, to deepen our understanding of its population dynamics. Indeed, in a context where long-distance dispersal is disadvantageous, an aerial seed bank could effectively result in a successful strategy for seedling survival, by ensuring anchorage at the "mother-site".

Aerial seed banks can also protect seeds from soil-dwelling granivorous [28,39]. There is a general agreement that granivorous ants can cause substantial seed losses in a variety of ecosystems [51]. Given that ants can also serve as dispersal agents (myrmecochory), it is necessary to evaluate the outcome of the ant-seed interactions, to determine whether ants are better classified as seed predators or dispersers [52]. In non-myrmechorous species, it has been estimated that ants can collect more than $85 \%$ of seeds, and almost $70 \%$ of them can be effectively lost, due to predation [52]. Our observations suggest that seeds of P. palinuri could be subjected to ants' post-dispersal predation, as also already reported in many other species of Primula $[10,11,50,53]$. Although it has been observed that granivorous ants can collect seeds directly from plants $[37,53]$, we did not observe this phenomenon in open capsules of P. palinuri. A strategy of predation avoidance in P. palinuri has already been pointed out: P. palinuri accumulates phenolic compounds in its seedling roots that act as a feeding deterrent [21]. Nevertheless, we cannot exclude that some proportion of the seeds are also safely dispersed by ants, as observed in other plants $[37,49,51,52]$. Therefore, further studies are needed to clarify relationships between P. palinuri and granivorous ants.

\section{Conclusions}

The present study investigated the seed release strategy adopted by P. palinuri on the vertical cliffs, along the Tyrrhenian coast of southern Italy, highlighting, for the first time, the occurrence of serotiny in Primula species. Our results demonstrate that P. palinuri is a serotinous species in which seed release occurs only in response to cycles of moisture following dry periods. Once capsules open, seeds are not released at the same time. Indeed, capsules repeatedly open when dry, and close again when moistened. Vertical cliffs, the natural habitat of P. palinuri, consist of high and very steep rock walls characterized by a set of peculiar environmental factors, due to verticality, and where water availability is one of the most limiting factors. The ability of P. palinuri to distribute seed release over time can be interpreted as an opportunistic strategy to cope with the uncertainty of environmental conditions. Overall, seedling recruitment is the bottleneck in the life cycle, and generation turnover of P. palinuri and seed production before the summer allows the species to cope with the aridity season. This phenological adaptation, together with the aerial seed bank, the serotiny and the peculiar opening/closing mechanism of the capsules, represent a unique strategy for a progressive seed release which helps ensure the persistence of P. palinuri on Mediterranean coastal cliffs.

Supplementary Materials: The following are available online at http://www.mdpi.com/1424-2818/12/8/291/s1, Video S1: Seeds of Primula palinuri picked up by Messor spp. ants.

Author Contributions: R.S. and G.A. conceived and designed the experiments. G.A. and M.B. conducted the field work. R.S. performed the laboratory experiments and analyzed the data. R.S. and L.G.I. wrote the manuscript and generate the electronic Supplementary Materials. G.A. edited the manuscript. All authors approved the final manuscript. All authors have read and agreed to the published version of the manuscript.

Funding: This research received no external funding.

Acknowledgments: Authors acknowledge Chiara Buonanno for video recording the seed pick up by ants. Capsules and seeds used for laboratory tests were kindly provided by the Botanical Garden of Portici $\left(40^{\circ} 48^{\prime} 42^{\prime \prime} \mathrm{N}\right.$ $14^{\circ} 20^{\prime} 38^{\prime \prime}$ E). Data associated with this paper are available in Zenodo: http://dx.doi.org/10.5281/zenodo.3876871.

Conflicts of Interest: The authors declare no conflict of interest.

\section{References}

1. Hewitt, G. The genetic legacy of the quaternary ice ages. Nature 2000, 405, 907-913. [CrossRef] [PubMed]

2. Médail, F.; Diadema, K. Glacial refugia influence plant diversity patterns in the Mediterranean Basin. J. Biogeogr. 2009, 36, 1333-1345. [CrossRef] 
3. Larson, D.W.; Matthes, U.; Kelly, P.E. Cliff Ecology: Pattern and Process in Cliff Ecosystems; Cambridge University Press: Cambridge, UK, 2005; ISBN 0521019214.

4. Davis, P.H. Cliff vegetation in the eastern mediterranean. J. Ecol. 1951, 39, 63-93. [CrossRef]

5. Cooper, A. Plant species coexistence in cliff habitats. J. Biogeogr. 1997, 24, 483-494. [CrossRef]

6. Aronne, G.; De Micco, V.; Santangelo, A.; Santo, A.; Buonanno, M. Coastal vertical cliffs of the National Park of Cilento: Reservoirs of endemic species. Latest Trends Eng. Mech. Struct. Eng. Geol. 2014, 26, 77-85.

7. Lavergne, S.; Thompson, J.D.; Garnier, E.; Debussche, M. The biology and ecology of narrow endemic and widespread plants: A comparative study of trait variation in 20 congeneric pairs. Oikos 2004, 107, 505-518. [CrossRef]

8. Richards, J. Primula; Pavilion Books: London, UK, 2014; ISBN 1849942412.

9. Darwin, C. On the two Forms, or dimorphic condition, in the species of Primula, and on their remarkable sexual relations. J. Proc. Linn. Soc. London. Bot. 1862, 6, 77-96. [CrossRef]

10. Ehrlén, J.; Käck, S.; Ågren, J. Pollen limitation, seed predation and scape length in Primula farinosa. Oikos 2002, 97, 45-51. [CrossRef]

11. Antrobus, S.; Lack, A.J. Genetics of colonizing and established populations of Primula veris. Heredity 1993, 71 , 252-258. [CrossRef]

12. Ritchie, J.C. Primula Scotica hook. J. Ecol. 1954, 42, 623. [CrossRef]

13. Davidson, J.B.; Wolf, P.G. Natural history of maguire primrose, Primula cusickiana var. Maguirei (Primulaceae). West. North Am. Nat. 2012, 71, 327-337. [CrossRef]

14. Crema, S.; Cristofolini, G.; Rossi, M.; Conte, L. High genetic diversity detected in the endemic Primula apennina Widmer (Primulaceae) using ISSR fingerprinting. Plant Syst. Evol. 2009, 280, 29-36. [CrossRef]

15. Jiménez, A.; Mansour, H.; Keller, B.; Conti, E. Low genetic diversity and high levels of inbreeding in the Sinai primrose (Primula boveana), a species on the brink of extinction. Plant Syst. Evol. 2014, 300, 1199-1208. [CrossRef]

16. Zhang, L.B.; Kadereit, J.W. Classification of Primula sect. Auricula (Primulaceae) based on two molecular data sets (ITS, AFLPs), morphology and geographical distribution. Bot. J. Linn. Soc. 2004, 146, 1-26.

17. Aronne, G.; Arena, C.; De Micco, V.; Giovanetti, M.; Buonanno, M. Full light and soil drought constrain plant growth in Mediterranean cliffs: The case of Primula palinuri Petagna. Plant Biosyst. 2018, 152, 863-872. [CrossRef]

18. De Micco, V.; Aronne, G. Occurrence of morphological and anatomical adaptive traits in young and adult plants of the rare mediterranean cliff species Primula palinuri Petagna. Sci. World J. 2012, 2012, 471814. [CrossRef]

19. Aronne, G.; Buonanno, M.; De Micco, V. Assessment of distyly syndrome in Primula palinuri Petagn. a rare species living on maritime vertical cliffs. Plant Syst. Evol. 2013, 300, 917-924. [CrossRef]

20. Strumia, S.; Buonanno, M.; Aronne, G.; Santo, A.; Santangelo, A. Monitoring of plant species and communities on coastal cliffs: Is the use of unmanned aerial vehicles suitable? Diversity 2020, 12, 149. [CrossRef]

21. Aronne, G.; De Micco, V.; Barbi, S. Hypocotyl features of Primula palinuri Petagna (Primulaceae), an endemic and rare species of the Southern Tyrrhenian Coast. In Proceedings of the Ecologia Emergenza Pianificazione, 18th Congresso Nazionale della Società Italiana di Ecologia (SItE '10), Cagliari, Italy, 12-14 September 2010; Società Italiana di Ecologia: Parma, Italy, 2010; pp. 113-119.

22. Aronne, G.; Buonanno, M.; De Micco, V. Reproducing under a warming climate: Long winter flowering and extended flower longevity in the only Mediterranean and maritime Primula. Plant Biol. 2014, 17, 535-544. [CrossRef]

23. Aronne, G.; Wilcock, C. Reproductive phenology in Mediterranean macchia vegetation. Lagascalia 1997, 19, 445-454.

24. Mitrakos, K. A theory for Mediterranean plant life. Acta Oecologica Oecologia Plant. 1980, 1, $245-252$.

25. Herrera, J. Flowering and fruiting phenology in the coastal shrublands of Doñana, south Spain. Vegetatio 1986, 68, 91-98.

26. Baskin, C.C.; Baskin, J.M. Seeds: Ecology, Biogeography, and Evolution of Dormancy and Germination; Elsevier Science: San Diego, CA, USA, 2014; ISBN 0124166830.

27. Van der Pijl, L. Principles of Dispersal in Higher Plants; Springer: Berlin/Heidelberg, Germany, 1969; ISBN 978-3-642-96110-6. 
28. Lamont, B.B.; Enright, N.J. Adaptive advantages of aerial seed banks. Plant Species Biol. 2000, 15, 157-166. [CrossRef]

29. Lamont, B.B.; Le Maitre, D.C.; Cowling, R.M.; Enright, N.J. Canopy seed storage in woody plants. Bot. Rev. 1991, 57, 277-317. [CrossRef]

30. Gao, R.; Yang, X.; Yang, F.; Wei, L.; Huang, Z.; Walck, J.L. Aerial and soil seed banks enable populations of an annual species to cope with an unpredictable dune ecosystem. Ann. Bot. 2014, 114, 279-287. [CrossRef]

31. Lamont, B.B. Canopy seed storage and release: What's in a name? Oikos 1991, 60, 266-278. [CrossRef]

32. Saracino, A.; Bellino, A.; Allevato, E.; Mingo, A.; Conti, S.; Rossi, S.; Bonanomi, G.; Carputo, D.; Mazzoleni, S. Repeated stand-replacing crown fires affect seed morphology and germination in Aleppo pine. Front. Plant Sci. 2017, 8, 1160. [CrossRef]

33. Bastida, F.; González-Andújar, J.L.; Monteagudo, F.J.; Menéndez, J. Aerial seed bank dynamics and seedling emergence patterns in two annual Mediterranean Asteraceae. J. Veg. Sci. 2010, 21, 541-550. [CrossRef]

34. Zedler, P.H. Closed-cone conifers of the chaparral. Fremontia 1986, 14, 14-17.

35. Rossi, S.; Morin, H.; Gionest, F.; Laprise, D. Inter-and intra-annual patterns of seed rain in the black spruce stands of Quebec, Canada. IForest 2017, 10, 189-195. [CrossRef]

36. Martínez-Berdeja, A.; Ezcurra, E.; Sanders, A.C. Delayed seed dispersal in California deserts. Madroño 2015, 62, 21-32. [CrossRef]

37. Bastida, F.; Talavera, S. Temporal and spatial patterns of seed dispersal in two Cistus species (Cistaceae). Ann. Bot. 2002, 89, 427-434. [CrossRef] [PubMed]

38. Parolin, P. Ombrohydrochory: Rain-operated seed dispersal in plants-with special regard to jet-action dispersal in Aizoaceae. Flora Morphol. Distrib. Funct. Ecol. Plants 2006, 201, 511-518. [CrossRef]

39. Günster, A. Seed bank dynamics - longevity, viability and predation of seeds of serotinous plants in the central namib desert. J. Arid Environ. 1994, 28, 195-205. [CrossRef]

40. Fox, G.A. Failure time analysis: Studying times-to-events and rates at which events occur. In Design and Analysis of Ecological Experiments; Scheiner, S.M., Gurevitch, J., Eds.; Oxford University Press: New Yor, NY, USA, 2001; pp. 253-289. ISBN 9780195131888.

41. Lee, E.T.; Wang, J. Statistical Methods for Survival Data Analysis; John Wiley \& Sons: Hoboken, NJ, USA, 2003; ISBN 9780471369974.

42. R, Development Core Team. R: A Language and Environment for Statistical Computing; R Foundation for Statistical Computing: Vienna, Austria, 2018.

43. Wollenweber, E.; Schneider, H. Lipophilic exudates of pteridaceae-Chemistry and chemotaxonomy. Biochem. Syst. Ecol. 2000, 28, 751-777. [CrossRef]

44. Strumia, S.; Croce, A.; Santangelo, A. New distributional data of the rare endemic species Eokochia saxicola (Guss.) Freitag and G. Kadereit (Chenopodiaceae): Effects on biogeography and conservation. Plant Biosyst. 2015, 149, 559-564. [CrossRef]

45. Barone Lumaga, M.R.; Santangelo, A.; Strumia, S. Morpho-functional traits influencing the fitness of highly endangered Eokochia saxicola (Guss.) Freitag \& G. Kadereit (Amaranthaceae). Flora Morphol. Distrib. Funct. Ecol. Plants 2016, 218, 11-17.

46. Baker, E.A.; Hunt, G.M. Erosion of waxes from leaf surface by simulated rain. New Phytol. 1986, 102, 161-173. [CrossRef]

47. Van Oudtshoorn, K.V.R.; Van Rooyen, M.W. Dispersal Biology of Desert Plants; Adaptations of Desert Organisms; Springer: Berlin/Heidelberg, Germany, 2013; ISBN 3662035618.

48. Lamont, B.B.; Groom, P.K. Seed and seedling biology of the woody-fruited proteaceae. Aust. J. Bot. 1998, 46, 387-406.

49. Valverde, T.; Silvertown, J. An integrated model of demography, patch dynamics and seed dispersal in a woodland herb, Primula vulgaris. Oikos 1997, 80, 67-77. [CrossRef]

50. Valverde, T.; Silvertown, J. Spatial variation in the seed ecology of a woodland herb (Primula vulgaris) in relation to light environment. Funct. Ecol. 1995, 9, 942-950. [CrossRef]

51. MacMahon, J.A.; Mull, J.F.; Crist, T.O. Harvester ants (Pogonomyrmex spp.): Their community and ecosystem influences. Annu. Rev. Ecol. Syst. 2000, 31, 265-291. [CrossRef] 
52. Retana, J.; Picó, F.X.; Rodrigo, A. Dual role of harvesting ants as seed predators and dispersers of a non-myrmechorous Mediterranean perennial herb. Oikos 2004, 105, 377-385. [CrossRef]

53. Leimu, R.; Syrjänen, K.; Ehrlén, J.; Lehtilä, K. Pre-dispersal seed predation in Primula veris: Among-population variation in damage intensity and selection on flower number. Oecologia 2002, 133, 510-516. [CrossRef] [PubMed] 